Copyright (C) 2018 by Academic Publishing House Researcher

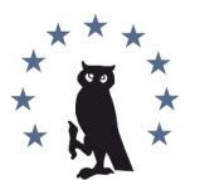

Published in the Russian Federation

European Researcher. Series A

Has been issued since 2010.

ISSN 2219-8229

E-ISSN 2224-0136

2018, 9(1): 42-49

DOI: 10.13187/er.2018.1.42

www.erjournal.ru

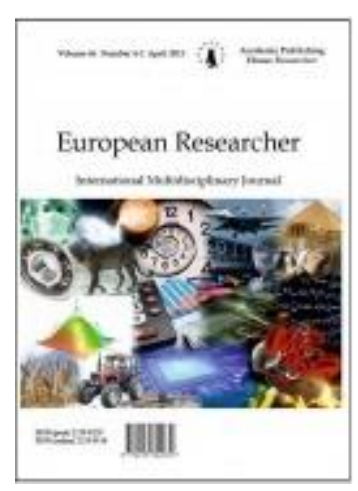

\title{
Social Adaptability of Elementary School Gifted Students
}

\author{
Amina Osmanović ${ }^{a},{ }^{*}$, Ceylani Akay a \\ ${ }^{a}$ International Burch University, Bosnia and Herzegovina
}

\begin{abstract}
In this paper, we have tried to reach an understanding on social adaptability of gifted students in the educational context which has not been adapted to the specific needs of a gifted child. The sample consisted of 43 gifted fourth grade students and their peers (in total: 469 students). The first research question examined the differences in the level of social skills development of sampled gifted students measured by the seven scaled Social Skills SelfAssessment Tool. The results showed that the best scores were achived on the scales of Social and Emotional Sensitivity and Expressiveness. Gifted students underscored the scale of Social Manipulation. The second research question examined the differences in the sociometric position of gifted students. By analyzing the data of the sociogram, we have realised that only 10 (23.25\%) of the 43 gifted students belong to a group of popular children or "stars". Obtained results proved significant differences in the sociometric position of fourth grade gifted students in the classroom. Measurement of social adaptability in a group of gifted students did not reveal that gifted people demonstrate high levels of social competence. Consequently, results presented that only 8 (18.6\%) of the 43 gifted students belong to a group of individuals that are socially adapted: high level of social skills combined with high sociometric position.
\end{abstract}

Keywords: giftedness, socialization, social adaptability, social skills, sociometric position.

\section{Introduction}

Although scientific approaches to understanding giftedness have made a significant shift from the original understanding of giftedness as a predetermined personality trait with numerous mystical properties, this phenomenon has not been fully clarified. The reason may be in the inability to contextualize giftedness in determined and final theoretical discourses, as well as, evident complexity of this phenomenon.

Social aspect, which we sought to investigate in this paper, refers to the possibility of social adaptability of gifted students in the real environment, school. Previous studies carried out in this area indicate that the answers to this question are different and very often contradictory in nature. The first approach is close to understanding that gifted people, due to their cognitive capacities, are able to better understand themselves and others, and thus better manage stressful and conflicting social interactions which enables them better social adaptability (Betts, Neihart, 1988). The second stand represents the idea that gifted individuals, given their pronounced emotional and moral sensitivity, have a greater chance to face the challenges in the process of social adaptation (Neihart,

\footnotetext{
${ }^{*}$ Corresponding author

E-mail addresses: aminaceho@gmail.com (A. Osmanović), ceylani.akay@ibu.edu.ba (C. Akay)
} 
1999). When we look more closely at the personality characteristics of gifted individuals, we can not resist the view that both positions are profound (Akbarov, Osmanović, 2014).

The quality of the overall relations in the class will create a specific classroom climate that will be either stimulating or depressing to the development of personality traits of gifted individuals. That is the valuable process of the formation of student's identity in accordance with the dominant socio-cultural context. The child meets with the authority of the teacher in the school, with the group demands and needs (which may be in disagreement with the child's own needs), with the request to control certain behaviors that have not been imposed in other circumstances. All social processes mentioned above contribute to the understanding that certain interventions are needed in a child's behavior to be accepted by society.

The aim of this research is to measure social adaptability of gifted students. For the purpose of this study, the concept of social adaptability has been operationalized as a high level of social skills combined with high sociometric position.

\section{Review of Literature}

Considering that our work explores the concept of social adaptability, which is exclusively a social component and derives from the process of socialization, it is inevitable to consider the theoretical aspect of the notion of socialization. One of the simplest definitions of socialization is that it is "social learning realized by inaction with other people" (Rot, 1977: 117).

Social intelligence is yet one more important concept closely linked to the process of socialization. According to Riggio and Reichard (2008: 171), the fundamental concept of social intelligence are social skills. They define social skills as „the ability to express oneself in social interactions, the ability to "read" and understand different social situations, knowledge of social roles, norms, and scripts, interpersonal problem-solving skills, and social role-playing skills“. Most authors imply that social skills are a developmental concept in nature and that they evolve via social interactions. Marlowe defines social skills as "the ability to understand the feelings, thoughts, and behaviors of persons including onself, in interpersonal situations and to act appropriately upon that understanding (Marlowe, 1986: 52)

Hence, only behavior that respects feelings, thoughts, and behaviors of other people can be considered as a socially skilled behavior. Appropriate social development requires knowledge and understanding of the norms, rules and values of the community and culture in which an individual lives or deals, as well as mastering the skills necessary for effective interaction within that community. The child who has succeeded this, has developed the skills of social competence.

By reviewing the literature that is closely concerned with this topic, it has been found that the general framework of social skills states: sensitivity, expression and control as the three primary skills that occur in the emotional-non-verbal and social-verbal domain (Riggio, Reichard, 2008). In the emotional-non-verbal domain, there is emotional expression, emotional sensitivity and emotional control, and within the social-verbal domain there is social expressiveness, social sensitivity and social control. For someone, we say that he/she is adapted when there is a harmony between his/her notions of self, others, the world, and objective reality. The state of social adaptability is, therefore, the agreement between the reference frame on the one hand and the world on the other, that is, between theory and practice (Milivojević, 2008).

Bloom's studies (1982, as cited by Čudina-Obradović, 1991) points out that gifted children have a greater need for self-worthiness and competence. Realization of self-confidence with their own activity is a much greater reward for them than for other individuals. Because they have great abilities, their activities often lead to high quality results, which directly affects the development of a sense of competence. These findings are based on the presence of the persistence of these individuals in different areas of their talents. Unlike Bloom, Feldman (1987 as cited by ČudinaObradović, 1991) points out that wider social factors, from the broadest historical cultural events to the immediate environment, are as important in the development of the inherited potential of an individual. These factors are the readiness of society (technical and general developmental level that enables society to recognize and appreciate a certain type or combination of abilities), readiness of the immediate environment to recognize and invest efforts in developing this ability, and opportunities for quality education and mentoring.

If we know that the results of one's own achievements are necessary in order for a gifted individual to build a positive image of himself, then it is clear that talented people must have the 
opportunity to show their potential, and to provide them with the chance to achieve the goals and tasks they are striving for and for which they are predisposed. Studying in an environment in which gifted students are marked as "different" will significantly degrade selfperception.

\section{Method}

The aim of this study is to explore social adaptability of gifted students. To achieve our aim, we measured the level of social skills and the sociometric position of gifted students according to the following questions:

1. Is there a statistically significant difference in results on the Social Skills Inventory?

2. Is there a significant difference in the sociometric position within the classroom?

3. Is there a statistically significant correlation between the results of the Social Skills Inventory and the sociogram results?

The following hypotheses have been tested:

Ho1 - There is no statistically significant correlation difference in results on Social Skills Inventory.

Ho2 - There is no statistically significant correlation in the sociometric position of fourth grade gifted students in the classroom.

Ho3 - There is no statistically significant correlation between the results of the Social Skills Inventory and sociogram results.

\subsection{Participants}

The sample of this research is intentional and consists of fourth grade students from nine elementary schools from the Novi Grad municipality in Bosnia and Herzegovina. In this study, 43 gifted students and 426 peer students participated. Gifted students have been identified within the "Specially Targeted Project" supported by UNDP and academic staff from Department of Pedagogy (Faculty of Philosophy, University of Sarajevo). The identification process was conducted by a set of standardised instruments.

\subsection{Instruments and procedure}

\subsubsection{Social Skills Self-Assessment Tool}

This research applied the Social Skills Self-Assessment Tool developed by the researcher with the help of a supervisor. The test is an adapted and translated version of the Social Skills Inventory Ronald Riggio (Riggio, 1986: 649-660). The questionnaire includes four dimensions of social skills: sensitivity, expressiveness, control and manipulation. The inventory consists of 28 items, which content and terminology is adapted to the lower grades elementary school students.

\subsubsection{Sociometric questionnaire / sociogram}

In this research, a sociogram questionnaire consisting of eight questions was designed. In order to avoid choices favoring the criteria that are not relevant for this research (eg. socioeconomic status, students' success in school), general claims have been avoided (for example: I would prefer to sit with claims related to social skills.

We have selected the following sociometric categories:

- Popular children - "stars" - those children who have five or more positive votes, and none is negative.

- Unpopular children - "discarded" or "isolated" - are children with four or more negative votes, and none positive.

- Medium-rated - the third category consists of children with more than five positive and less than four negative votes. Such children have a lot of positive votes, however as they are chosen for a negative criterion, they can not be classified into the "stars" group. Also, as they have less than four negative votes, they do not belong to the group of "isolated", unpopular children.

The term "sociometric position " refers to the number of positive or negative choices by the members of the group to which the individual belongs. The basic distinction between popular children ("stars") and those who are not there is in the absence of negative votes. 


\subsection{Data analysis}

For the purpose of statistical data analysis Statistical Package for Social Sciences (SPSS) was used. Descriptive statistics (means, standard deviations, and medians) were conducted, as well as chi-square coefficient was obtained.

\section{Results \\ 4.1. The differences in results on Social Skills Inventory between fourth grade gifted students.}

The first research question examined the level of social skills development of sampled gifted students. Based on the obtained answers from Social Skills Self-Assessment Tool and the descriptive statistics data, we clustered respondents into two groups (above and below the average results). After the division, a statistically significant difference in the number of respondents was not located between those who achieved above (22 students or $51.16 \%$ ) and below (21 students or $48.84 \%)$ the average results. The statistically significant difference was found in three out of seven individual sub-scales of SSI questionnaire. Those are the Emotional Sensitivity, the Emotional Expressiveness and the Social Sensitivity subscales (Table 1).

Table 1. Descriptive statistics for Social Skills Self-Assessment Tool

\begin{tabular}{cccccccc}
\hline & $\begin{array}{c}\text { Emotional } \\
\text { Expressiveness }\end{array}$ & $\begin{array}{c}\text { Emotional } \\
\text { Sensitivity }\end{array}$ & $\begin{array}{c}\text { Emotional } \\
\text { Control }\end{array}$ & $\begin{array}{c}\text { Social } \\
\text { Expressiveness }\end{array}$ & $\begin{array}{c}\text { Social } \\
\text { Control }\end{array}$ & $\begin{array}{c}\text { Social } \\
\text { Sensitivity }\end{array}$ & $\begin{array}{c}\text { Social } \\
\text { Manipulation }\end{array}$ \\
\hline Mean & 20,88 & 23,93 & 14,65 & 24,67 & 17,86 & 23,48 & 12,06 \\
Mode & 17 & 24 & 13 & 24 & 16 & 26 & 12 \\
Median & 21 & 24 & 15 & 25 & 17 & 24 & 12 \\
\hline
\end{tabular}

Table 1 shows the calculated values of the mean, the mode and the median for the Social Skills Self-Assessment Tool results of gifted children from the sample, in each of the seven subscales (Emotional Expressiveness, Emotional Sensitivity, Emotional Control, Social Expressiveness, Social Control, Social Sensitivity and Social Manipulation). The descriptive results show that the best scores were achieved on the scales of Social and Emotional Sensitivity and Expressiveness. Gifted students received very low results of the scale of Social Manipulation.

\subsection{The differences in the sociometric positions of fourth grade gifted students in the classroom}

By analyzing the data of the sociogram, we have realised that only 10 (23.25\%) of 43 gifted students belong to a group of popular children or "stars". In the "medium-rated" and "Unpopular" groups, similarly, 16 gifted students $(37.21 \%)$ were categorized.

Although some gifted students from the sample had a large number of positive votes, the negative votes they received from their peers were eliminative for their classification in the 'star' category. The Ho2 hypothesis was rejected. The obtained results provided a significant difference in the sociometric position of fourth grade gifted students in the classroom.

\subsection{The correlation between the results of the Social Skills Self-Assessment Tool and sociogram results.}

The third research question was to examine the relationship between the results of Social Skills Self-Assessment Tool and the results of the sociogram of gifted students. A chi-square was calculated to determine whether there is a statistically significant relation between the level of social skills and the sociogrammatic position of gifted students. The chi-square is an appropirate statistical tool if the indicators are quantitative or qualitative in nature as qualitative indicators are expressed in absolute frequencies and converted into quantitative indicators. Also, we can test one or more dependent or independent samples by multiple features or by the same feature with multiple modalities. 
Table 2. Calculate the Chi-square between social skills and the sociometric position of gifted students

\begin{tabular}{|c|c|c|c|c|}
\hline$f_{o}$ & $\mathbf{f}_{t}$ & $\mathbf{f}_{\mathbf{o}}-\mathbf{f}_{t}$ & $\left(f_{0}-f_{t}\right)^{2}$ & $\left(f_{o}-f_{t}\right)^{2} / f_{t}$ \\
\hline 6 & 8,18 & $-2,18$ & 4,75 & 0,58 \\
\hline 10 & 7,81 & 2,19 & 4,79 & 0,61 \\
\hline 8 & 5,11 & 2,89 & 8,35 & 1,63 \\
\hline 2 & 4,88 & $-2,88$ & 8,29 & 1,69 \\
\hline 8 & 8,69 & $-0,69$ & 0,47 & 0,054 \\
\hline 9 & 8,30 & 0,70 & 0,49 & $\begin{array}{c}0,059 \\
\mathbf{X}^{\mathbf{2}}=\mathbf{4 , 6 2 3}\end{array}$ \\
\hline
\end{tabular}

The number of degrees of freedom is $(2-1) \times(3-1)=2$. The table shows that the limit value of the $\chi_{2}$ with 2 degrees of freedom, and at a significance level of $1 \%$, is 9.21. The calculated Chisquare is less than the limit value $\chi^{2}$ at the significance level of $1 \%(9.21)$ and is 4.623 , so we reject the hypothesis (there is no statistically significant correlation between the results of the Social Skills Inventory and sociogram results), and we conclude that these two variables are related.

Table 3. Number of socially skilled gifted studensts and gifted students with the lack of social skills by sociometric categories

\begin{tabular}{cccc}
\hline & $\begin{array}{c}\text { Gifted students with the } \\
\text { lack of social skills }\end{array}$ & $\begin{array}{c}\text { Socially skilled gifted } \\
\text { students }\end{array}$ & Total \\
\hline Isolated & 10 & 6 & 16 \\
Medium-rated & 9 & 8 & 17 \\
'Stars' & 2 & 8 & 10 \\
Total & 21 & 22 & 43 \\
\hline
\end{tabular}

As we can see from the Table 2, eight socially skilled gifted students are class "stars", and only two "stars" of departments have a lack of social skills. It is indicative that eight out of a total of ten popular children have developed social skills. This would mean that social skills were realized in a social context (in the classroom), and gifted students are therefore recognized as superior to other peers in the classroom within the framework of social competences that were set out in a sociometric questionnaire.

\section{Discussion and conclusion}

Measurement of social adaptability in a group of gifted students did not prove that gifted people demonstrate high levels of social competence. Our hypothesis was rejected as only 8 (18.6\%) of 43 gifted students belong to a group of individuals that are socially adapted: high level of social skills combined with high sociometric position. The reasons for the poor social adaptability of the sampled gifted students can be found in the specific characteristics of gifted (asynchronity of development, emotional sensitivity, neurotic perfectionism, desire to work in their own way, feeling that they are different from chronological peers, nonconformism), but also in the socio-cultural factors (educational institution that is not able to satisfy the academic needs of the talented, established sociological criterions that mark anyone who deviates from the norm).

As this study showed, the cognitive development of gifted students is considerably superior to the socio-emotional development. Thus, the disharmony of development influences reactions and behaviors that are not appropriate to the chronological age of gifted individuals, which can cause negative consequences for the processes of social adaptability in the real environment. Not all 
participants in the interaction with gifted individuals are willing to tolerate behaviors that are unusual and sometimes frustrating, and which are, in fact, one of the basic characteristics of gifted and their development.

The advantage, and at the same time the defect of gifted students, is a "polarized set of traits". Gifted individuals have certain advantages for the social skills development (high motivation and outstanding cognitive capacities), but at the same time, they have an emphasized emotional and moral sensitivity and expressivenes which makes social learning more difficult.

Although some gifted students from the sample have achieved excellent results on the Social Skills Self-Assessment Tool, they were not recognized as socially skilled within the positive categories of the sociometric questionnaire (the most entertaining/Has the most friends in the class/Understands everyone). Therefore, they do not fulfill the criterion of social adaptability (as it has been operationalized in our research: high level of social skills and a high sociometric position).

The results obtained in this study indicated that gifted students in the fourth grade of elementary school have different degrees of development of social skills. While some have achieved the maximum number of points in some subscales of the Social Skills Self-Assessment Tool, some have very low achievements. Therefore, it is impossible to make a general statement about the degree of development of social skills in gifted children. As presented in the results, there is no significant difference in the number of respondents who are in the group of above-developed social skills in relation to the group of respondents with below-developed social skills. In the Emotional and Social Sensitivity Scales, and the Emotional and Social Expression Scales respondents achieved the best results. Among the mentioned scales, the best result was achieved on the social expression scale. This social skill implies the ability of verbal expression and the ability to involve others in social interaction as well as leadership behaviors. On the scale of social expressiveness, the mean was 24.67 , and $44.18 \%$ of the respondents have below-average results, while $55.81 \%$ has aboveaverage results. Therefore, there is a significant difference between the number of subjects within these two groups. For these results, we can say that they were expected as the first indications about who could take the role of leader, both in class and in other life situations, are beginning to take place. Leadership technique implies a series of learning, and lasts throughout the course of education. Stastistically significant difference was also found on the Emocional Sensitivity and the social Sensitivity sub-scales.

As the data showed, the lowest scores were achieved on the Social Manipulation Scale $(M=12.06)$. Such results were realistic to expect. Social manipulation involves the ability to recognising and detect fraud. As we see, a good mastering of social manipulation involves highly developed analytical abilities (analyzing, evaluating, comparing, opposing) in concrete social relations and interactions. It is unjustifiable to expect ten-year old children to master this area of social skills.

The second step in reaching the goal of the research was to measure the sociometric position of gifted students in the classroom. The results of sociometric questionnaires represent a measure of the degree to which a student (in this particular case, a student with an identified giftedness) is engaged in activities highly valued by his school fellows or in accordance with the requirements of the group. The results showed that only 10 (23.25\%) out of 43 gifted students from the survey sample are "stars" of the class, and 16 students are positioned in the remaining two categories. The majority examined studies on this topic, regardless of differences in methodology, suggest that gifted students enjoy the same, and in some cases, greater popularity among peers (Austin, Draper, 1981; Luftig, Nichols, 1991; Norman et al., 2000, as cited by Altaras, 2006). However, as we see in the presented results, gifted students from our sample do not have a favorable sociometric position, which could have been influenced by a number of factors.

The gifted students from our sample attend the regular study program of the fourth grade of elementary schools (reformed education system). The sampled classrooms comprise 16 and more (up to 28) students of different general abilities. Such a program is adapted for an average student so that it can not meet the academic needs of gifted children for enriched and challenging educational content. Disappointment of academic needs is closely related to the occurrence of undesirable forms of behavior. The school is an important context for analyzing the behavioral characteristics of a child in a peer group, because establishing relationships with others allows meeting basic needs. We can talk about the innate need for belonging and adopting to a group that 
is spoken by most authors, mostly sociologists. If a good social climate is created in the classroom, the environment for the development of positive social relations will be created.

One of the variables not foreseen by this research, identified during the study, is the attitude of the teacher towards the gifted student as an important determinant of the quality of established relationships among peers. Namely, it was noticed that the teacher significantly determines the relation of other peers towards a gifted student by his attitude towards the gifted student. One possible consequence is the non-tactical emphasis on the superior characteristics of gifted students, which creates elite positions for these students. The results of the research show that only some gifted people are favored, while others fall into the category of being rejected because of underestimation of their peers, constant testing and attracting attention, due to selfishness, ignorance, incompatibility (Čudina-Obradović, 1991). Gifted pupils are often overly overestimated as students who enjoy greater popularity in the group they belong to, while withdrawn and shy learners are often unjustifiably not included among "gifted" even when they really belong to it (Cvetković Lay, Sekulić Majurec, 2008). Another possibility is that the teacher tries to establish a balance between students of different qualities by often hindering a gifted student to act in the department in accordance with his specificities (higher intrinsic motivation - the need for greater activity and influence, the desire to prove and competition with others, the desire to do things to exhaustion, the need for additional explanations, different dynamics of work) by insisting on equality. Gifted students, by continuous teacher intervention in their behavior, become marked by a negative criterion, which can define his/her status in the group and further relate to peers in the department. None of the two extremes of teachers' attitude toward gifted students is desirable.

As a third step in reaching the goal of the research, we tried to verify that there is a connection between social skills and a sociometric status. The calculated chi-square proved that there is a statistically significant correlation between the level of social skills and the sociogram position of the gifted student.

The question is: is social cognition 'literally translated' into social behavior and whether in the real social context the same 'assessment criteria' are applied as in the psychological test (Altaras, 2006: 107). Social competence does not always mean social acceptance from a peer group. The reason for this can be a number of factors, and this is evidenced by socially skilled students from this research (14 of them) who, despite excellent results in the Social Skills Self-Assessment Tool, have been socially rejected by their peers in the department. However, the computed chisquare has shown that there is a statistically significant connection between social competence and the sociometric situation of students. We conclude that the students who are socially competent and multiply positively chosen, have mastered a certain component of social skills that helped them to be accepted by most of their peers.

We can also talk about some of the disadvantages of this research, which primarily relates to the instrument used. Since the Social Skills Self-Assessment Tool is a self-assessment questionnaire, it is possible that some of the respondents gave socially desirable answers.

The obtained data on the low sociometric position of gifted individuals symptomatically indicate the need for an adequate plan and program for this group of students and for the necessary individual approach, so that they do not suffer the psycho-emotional consequences of this kind of "treatment" of the group. Because of the non-stimulating program, gifted children are often bored in school. One of the negative outcomes is the possiblity that gifted students would hide their talents in order not to assimiliate in the group, which may sometimes mean permanent loss of the priceless treasure that every gifted individual represents.

\section{References}

Akbarov, Osmanović, 2016 - Akbarov, A., Osmanović, A. (2016). Sociogramski položaj nadarenih učenika četvrtog razreda osnovne škole, Didaktički putokazi, 74, 44-48.

Altaras, 2006 - Altaras, A. (2006). Nadarenost i podbacivanje, Pančevo: Mali Nemo.

Betts, Neihart, 1988 - Betts, G.T., Neihart, M. (1988). Profiles of the gifted and talented. Gifted Child Quarterly, 32(2), 248-253. Retrieved from http://journals.sagepub.com/doi/pdf/ 10.1177/001698620404800102.

Cvetković-Lay, Sekulić Majurec, 2008 - Cvetković-Lay, J., Sekulić Majurec, A. (2008). Nadareno je, što ću s njim?, Zagreb: Alinea. 
Čudina-Obradović, 1991 - Čudina-Obradović, M. (1991). Nadarenost; razumjevanje, prepoznavanje, razvijanje, Zagreb.

Marlowe, 1986 - Marlowe, H.A. (1986). Journal of Educational Psychology, Vol 78(1), 52-58. Milivojević, 2008 - Milivojević, Z. (2008). Emocije, Novi Sad: Psihopolis institut.

Neihart, 2006 - Neihart, M. (2006). Affiliation/achievement conflicts in gifted adolescents, Bloomfield Hill: Roeper Review.

Riggio, 1986 - Riggio, R.E. (1986). Asscessment of Basic Social Skills, Fullerton, Journal of Personality and Social Psyhology, 51.

Riggio et al., 1989 - Riggio, R. E., Tucker, J., Coffaro, D. (1989). Social Skills and Empathy, Fullerton: Personality and Individual Differences, 10.

Riggio, Reichard, 2008 - Riggio, R.E., Reichard, R.J. (2008). The emotional and social intelligences of effective leadership: An emotional and social skill approach. Journal of Managerial Psychology, 23(2), 169-185. Retrieved from: http://www.emeraldinsight.com/doi/pdfplus/ 10.1108/02683940810850808

Rot, 1977 - Rot, N. (1977). Osnovi socijalne psihologije : socijalizacija, Beograd: Zavod za udžbenike i nastavna sredstva

Winner, 2005 - Winner, E. (2005). Nadarena djeca-mitovi i stvarnosti, Zagreb, Ostvarenje. 